\title{
¿Y tú qué vas a hacer con tu voto? Una mirada audiovisual al plebiscito sobre el Acuerdo de Paz de 2016 en Colombia
}

\author{
What will you do with your vote? An audiovisual look at the plebiscite on the \\ 2016 Peace Agreement at Colombia
}

\author{
Adolfo Baltar Moreno \\ Universidad Tecnológica de Bolívar, Cartagena, Colombia \\ https://orcid.org/0000-0002-1084-5045 \\ Yessica P. Blanco Torres ${ }^{2}$ \\ Universidad Tecnológica de Bolívar, Cartagena, Colombia \\ https://orcid.org/0000-0002-5082-2577 \\ Bene del Carmen Asprilla Mosquera ${ }^{3}$ \\ Universidad Tecnológica de Bolívar, Cartagena, Colombia \\ https://orcid.org/0000-0001-8974-3502
}

Artículo de investigación

Fecha de recepción: 24 de febrero de 2019

Para citar este artículo

Fecha de aceptación: 26 de abril de 2019

Baltar Moreno, A., Blanco Torres, Y. P., y Asprilla Mosquera, B. C. (2019). ¿Y tú qué vas a hacer con tu voto? Una mirada audiovisual al plebiscito sobre el Acuerdo de Paz de 2016 en Colombia. Campos en Ciencias Sociales, 7(2), 17-44. DOI: https://doi.org/10.15332/25006681.5030

1. Docente investigador y coordinador del semillero de investigación en Comunicación Política e Institucional, Universidad Tecnológica de Bolívar, Cartagena, Colombia. Correo electrónico: abaltar@utb.edu.co

2. Comunicadora social miembro del semillero de investigación en Comunicación Política e Institucional, Universidad Tecnológica de Bolívar, Cartagena, Colombia. Correo electrónico: jey-18@hotmail.com

3. Estudiante de Comunicación Social miembro del semillero de investigación en Comunicación Política e Institucional, Universidad Tecnológica de Bolívar, Cartagena, Colombia. Correo electrónico: basprillamosquera@ hotmail.com 


\section{RESUMEN}

Luego de más de cincuenta años de conflicto armado y casi cinco de negociaciones, el Gobierno colombiano y la guerrilla de las Farc firmaron un histórico acuerdo de paz que se sometió a plebiscito el 2 de octubre de 2016. Contra todo pronóstico, los detractores del acuerdo obtuvieron la victoria. Bajo este contexto, se desarrolló un trabajo de investigación audiovisual que vio sus frutos en la realización de ¿Y tú qué vas a hacer con tu voto? (2016) y Argumentos (2017), dos piezas audiovisuales producidas por el semillero de investigación en Comunicación Política e Institucional de la Universidad Tecnológica de Bolívar de Cartagena de Indias (Colombia). Estos productos, más allá de documentar las caras de la moneda que surgieron a partir de la contienda electoral entre partidarios y detractores del acuerdo de paz, exploran la complejidad de las diferentes perspectivas ideológicas, sociales y culturales que contribuyeron al resultado final de la votación.

Palabras clave: conflicto armado, investigación audiovisual, opinión pública, proceso de paz, semillero de investigación.

\section{Abstract}

After more than fifty years of armed conflict and almost five years of negotiations, the Colombian government and the Farc guerrillas signed a historic peace agreement that was submitted to a plebiscite on October 2 of 2016. Against all odds, the detractors of the agreement won. Under this context, two audiovisual works - What will you do with your vote? (2016) and Argumentos (2017)-, were produced by a research group of the Universidad Tecnológica de Bolívar in Cartagena de Indias (Colombia). These research films, beyond documenting the two perspectives that emerged from the electoral contest between supporters and opponents of the peace agreement, explore the complexity of the different ideological, social and cultural perspectives that contributed to the final result of the vote.

Keywords: Armed conflict, audiovisual research, peace process, public opinion, research incubator. 


\section{INTRODUCCIÓN}

Durante la segunda mitad del año 2016 Colombia fue centro de atención en las agendas informativas de los medios internacionales debido a que, tras más de cincuenta años de conflicto armado interno, el Gobierno colombiano y las Fuerzas Armadas Revolucionarias de Colombia (Farc) anunciaban un acuerdo de paz que supondría el fin de las hostilidades y la reintegración del grupo guerrillero a la vida política y civil. Un hecho que cobraría relevancia atendiendo a las cifras reportadas por el Centro Nacional de Memoria Histórica (2018), que dan cuenta de más de 260000 muertos desde el año 1958 a causa de este conflicto (eltiempo.com, 2018).

Las negociaciones para alcanzar este acuerdo, llevadas a cabo en La Habana (Cuba) desde el mes de septiembre de 2012 y lideradas por el presidente de la República, Juan Manuel Santos, habían sido permanentemente criticadas desde que se hicieron públicas por los sectores más conservadores del país, liderados por el senador y antecesor de Santos, el expresidente Álvaro Uribe. De este modo, todo el proceso de negociación se tuvo que desarrollar en un contexto de auge constante de la polarización política del país.

El grupo de las Farc ya había protagonizado en el pasado varios intentos fallidos de procesos de paz con el Estado, como los liderados por el Gobierno de Belisario Betancur en 1984, la iniciativa que transitó en los Gobiernos de Virgilio Barco y César Gaviria entre 1989 y 1992, la política de paz de Ernesto Samper en 1996, o las negociaciones en el Caguán entre 1999 y 2002 durante el Gobierno de Andrés Pastrana (Sánchez, 2014; Colprensa, 2016). Toda esta trayectoria en torno a la terminación del conflicto sentó los precedentes para que -luego de cuatro años de diálogo- el 26 de septiembre del año 2016 se pudiera firmar un acuerdo de paz que marcaría el fin de la que fue considerada la guerrilla más antigua de América Latina.

El acuerdo final al que llegaron el Gobierno Santos y las Farc presentó diversas directrices en torno a la implementación de una reforma rural integral, la apertura democrática, la terminación del conflicto, el manejo de las drogas ilícitas, el orden de la justicia transicional y la reparación de víctimas; así como los lineamientos de implementación y verificación de la aplicación del acuerdo. 
El texto final fue respaldado por más de 47 países, incluidos los cinco miembros del Consejo de Seguridad de la Organización de Naciones Unidas (ONU), así como por otros grandes organismos internacionales, como la Organización de Estados Americanos (OEA), la Unión Europea (UE) y la Unión de Naciones Suramericanas (Unasur). Además, ambas partes aceptaban someterse a una refrendación a través de un mecanismo de participación popular establecido por la Corte Constitucional. De esta forma, el acuerdo se firmaría públicamente en septiembre y se sometería a plebiscito el 2 de octubre de 2016 tomando como soporte la pregunta: ¿Apoya usted el acuerdo final para la terminación del conflicto y la construcción de una paz estable y duradera?

Figura 1. Extracto del documental con la portada de El Heraldo de Barranquilla, correspondiente al día 26 de septiembre de 2016

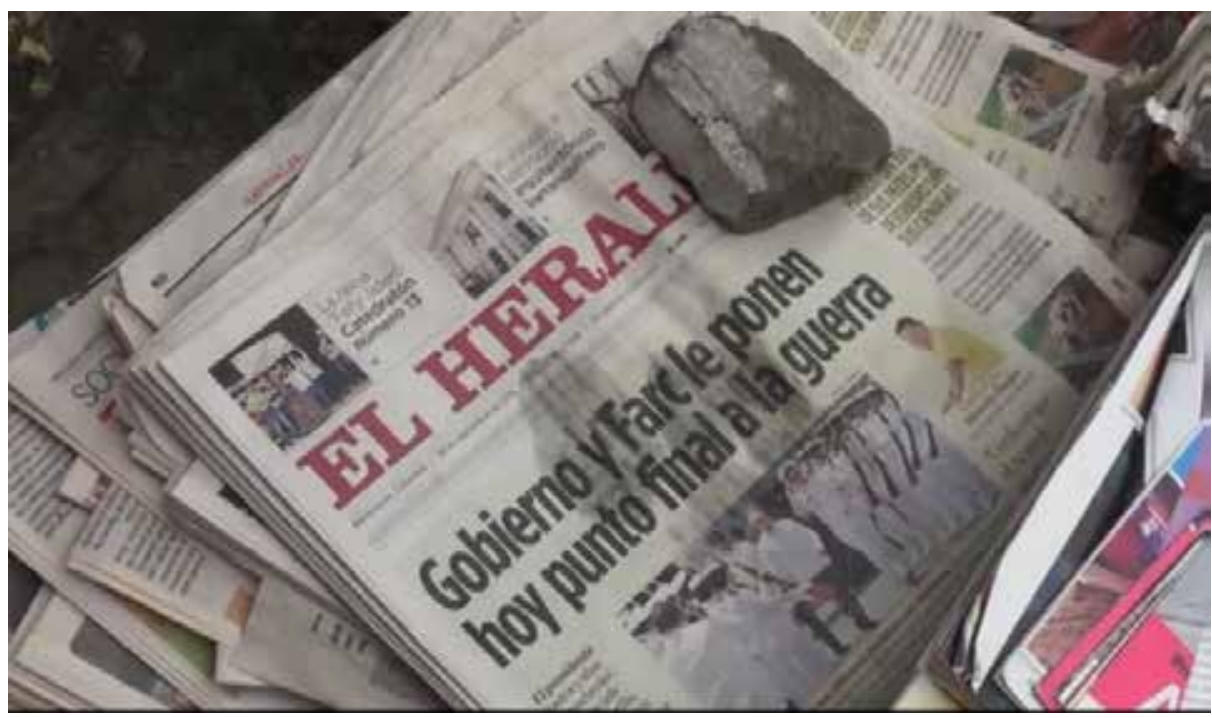

Fuente: elaboración propia.

En los inicios de septiembre, a un mes de la celebración del plebiscito, la mayoría de las encuestas de opinión realizadas por las grandes empresas de sondeos del país como Ipsos Napoleón Franco, el Centro Nacional de Consultoría (CNC), Cifras \& Conceptos, Invamer Gallup, la Encuesta de Opinión Nacional o el Opinómetro de 
Datexto, daban como claro vencedor la opción del Síal acuerdo, información que era publicada por Caracol y RCN, los medios de comunicación de cobertura nacional con mayor audiencia sobre el territorio (semana.com, 2016a; semana.com, 2016b). Pese a ello, en las calles de algunas ciudades, como lo fue el caso de Cartagena, la visibilidad de los partidarios del No era más que notable, y los rumores presentes en las conversaciones informales confirmaban un crecimiento sostenido de la intención de voto en este sentido.

No obstante, la ventaja del $S i$ frente al No se mantuvo hasta el final en las encuestas: tras la firma del acuerdo en Cartagena, una nueva encuesta publicada en el diario El Tiempo, reducía las distancias entre las dos opciones, pero el Sí mantenía todavía un margen de más de 18 puntos de ventaja ( $55 \%$ frente al $36.6 \%$ ). Esta encuesta además auguraba una participación por encima del $67 \%$ (eltiempo.com, 2016).

Desde que se hicieron públicas las conversaciones entre el Gobierno y la guerrilla en el año 2012, la batalla de los argumentos a favor y en contra del acuerdo se reflejó con toda su fuerza en redes sociales virtuales como Twitter, Facebook o YouTube. Durante todo el proceso negociador fue común encontrarse a diario con argumentos que soportaban las diversas posturas ciudadanas ante las negociaciones de paz que estaban teniendo lugar en La Habana. Algunos de los argumentos en contra del proceso procedían de mensajes difundidos en medios sociales que luego se demostraron falsos, como la supuesta impunidad de la que iban a gozar los autores de crímenes atroces, la presunta imposición de una ideología de género, la pérdida de los valores tradicionales cristianos de Colombia o la transformación del país en una sociedad al estilo Cubano o Venezolano.

En este importante contexto histórico surgió el interés del semillero de investigación en Comunicación Política e Institucional de la Universidad Tecnológica de Bolívar en Cartagena de Indias, de realizar una acción de investigación con los estudiantes orientada a explorar las opiniones y argumentos del ciudadano de a pie sobre el sentido del voto, buscando a su vez generar escenarios de diálogo y confrontación de discursos entre los participantes en la actividad. Se apostaba así al registro audiovisual de las reflexiones ciudadanas para la construcción de una narrativa 
basada en las percepciones presentes en la opinión pública, las posturas ideológicas y los diferentes conceptos de paz.

¿Qué estaba sucediendo entre la ciudadanía? ¿Realmente era tan fuerte la opción del Sí como predecían los sondeos? ¿Cómo se valoraba entre los ciudadanos del común la importancia histórica de la cita electoral? ¿Cómo se posicionaba ante los diferentes argumentos el ciudadano de a pie? ¿Cómo explorar el clima electoral con nuestros propios medios? Estas fueron las preguntas que se planteó el semillero de investigación cuando decidió dar inicio a la labor investigativa en las calles de Cartagena.

El equipo de trabajo propuso desarrollar una investigación videodocumental que permitiera registrar de forma fidedigna los discursos y argumentos por la paz presentes entre la opinión pública cartagenera frente al plebiscito. Como resultado se realizaron ¿Y tú qué vas a hacer con tu voto? (2016) y Argumentos (2017), dos producciones audiovisuales que hoy pretenden servir al diálogo ciudadano, a la construcción de paz y al fortalecimiento de la memoria sobre el conflicto armado colombiano.

\section{JUSTIFICACIÓN}

Históricamente el Estado colombiano se ha desarrollado sobre la base de una permanente bipolarización ideológico-partidaria que se traslada a las esferas sociales, y se traduce en la consolidación de conductas que procuran el rechazo u omisión de la otredad contraria a los principios propios (Herrera, 2013). En este sentido, trayendo a colación el escenario de concreción de un acuerdo de paz entre el Gobierno y la estructura guerrillera de las Farc, era de esperarse que la polarización tomara partido y definiera las direcciones que iban a tomar las opiniones de los ciudadanos de a pie respecto a este proceso.

Desde este enfoque, la iniciativa de registrar los argumentos y las intenciones de voto de los ciudadanos propuesta en este ejercicio buscó explorar el estado de esa polarización frente al plebiscito estableciendo diversos escenarios de debate que permitiesen a los ciudadanos anónimos tomar partido y expresarse ante la situación 
sociopolítica que atravesaba el país, apropiándose de la palabra para interpelar a los demás y generando mensajes que produjeran la representación de una conversación social cotidiana, buscando reproducir un ejercicio que algunos autores han definido como comunicación ciudadana (Rincón, 2007).

Es pertinente resaltar el doble sentido que toma esta investigación. Por un lado, es una llamada a la ciudadanía para hacer uso del lenguaje como instrumento que sirve a la construcción simbólica colectiva de un escenario donde coexisten la diferencia y la diversidad de pensamiento en torno a la definición de la paz y los modos en los que, como país, debemos determinar los medios para llegar a ella (Tíjaro, 2016). Por otro lado, es un ejercicio de escucha activa a través de la cámara, en la que cada una de las posiciones expresadas por los participantes merece su espacio de atención independientemente del sentido y el tono de su opinión.

Cerrando esta idea, es importante resaltar que el registro de las dinámicas sociales en torno a la toma de decisiones políticas tan trascendentales para el futuro del país, es también una apuesta por la creación de un material audiovisual que pueda servir para el estudio de la historia nacional y, en igual medida, al propósito de reconstruir la memoria colectiva para entender el porqué de las decisiones ciudadanas.

\section{MARCo TEÓRICO Y CONCEPTUAL}

Esta investigación centra su fundamentación teórica en la importancia que tiene la opinión pública en la construcción de la ciudadanía y la posterior toma de decisiones de los ciudadanos. Pese a que históricamente el concepto de opinión pública ha generado un gran debate en su afinación (Childs, 1965 y Bourdieu, 1973, citados en Sampedro y Resina, 2010), en este contexto se entiende este fenómeno como el proceso de construcción de ideas, argumentos y posiciones que adopta la ciudadanía frente al debate de temas de interés público que logran tomar gran relevancia dentro de un contexto social específico, y en el que existe una influencia decisiva de los líderes de opinión (Igartua y Humanes, 2010); y así mismo, al ejercicio de control que establecen los ciudadanos frente a las posiciones predominantes y su disposición 
a determinar aquello que es o no es aceptable bajo sus criterios (Noelle-Neumann, 2003).

Este abordaje supone a su vez una reflexión sobre la forma en que se construye la opinión pública y en la que los medios informativos tradicionales y los líderes de opinión (y hoy también los medios sociales) proporcionan a los individuos información que está por fuera de su experiencia directa para, a partir de la construcción de pseudoentornos, permitirles construir una opinión frente a aquellos eventos o situaciones que quedan por fuera de su cotidianidad (Lippmann, 1922; McCombs, 2006).

Este enfoque conecta teóricamente con los estudios de agenda setting y su relación con la forma en que los contenidos informativos sugieren a las audiencias los criterios a tener en cuenta para valorar ciertos temas, hechos o actores que hacen parte de la noticia -priming-; y el modo en que los atributos y encuadres direccionan los esquemas interpretativos de los individuos - framing- (McCombs y Shaw, 1972; McCombs, 2010).

Esta incidencia de los contenidos sobre las audiencias es mayor toda vez que los medios sociales ${ }^{4}$ y su soporte en las plataformas digitales, generan nuevas fuentes de información para la ciudadanía e impactan el establecimiento de la agenda pública (Sampedro y Resina, 2010; La Rosa, 2014; Campos-Domínguez, 2017).

Pese a ello, cabe indicar que, aunque los medios de comunicación tradicionales, los medios sociales (especialmente a través de las redes sociales virtuales como Twitter, Facebook, Instagram o YouTube) y los líderes de opinión influyen significativamente en la opinión pública, existen contextos en los que el público reacciona de manera inesperada y contraria a los lineamientos que se camuflan en los discursos dominantes (Sartori, 2007), dando lugar a razonamientos que emergen desde procesos de

4. Boyd (2011, p. 40) define a los medios sociales como "el espacio construido a través de la tecnología de redes" pero también como "el colectivo imaginado que surge como resultado de la intersección de las personas, la tecnología y la práctica”. 
interacción y reflexión de grupos de individuos que alimentan la categoría de lo que se ha denominado comunicación ciudadana.

He aquí el segundo concepto clave de esta investigación: la comunicación ciudadana. Rincón (2007) hace referencia a este concepto explicándolo como un proceso de comunicación social que llama a la formación de ciudadanías activas, que participan y crean unas esferas públicas de discusión y debate alternativas a las que se desprenden de la maquinaria mediática tradicional, y que propulsan las opiniones y argumentos del ciudadano de a pie; estos argumentos constituirían una opinión pública en un ejercicio que parte de la construcción de una conversación social cotidiana, donde priman las acciones comunicativas ciudadanas y convergen toda clase de discursos.

Este abordaje teórico hace que la importancia de la opinión pública y su relación con los procesos de comunicación ciudadana, confluyan para dar sentido al desarrollo de este trabajo, basado en una investigación videodocumental.

\section{La investigación videodocumental}

El uso de la cámara de video se ha abordado aquí como una posibilidad para construir conocimiento sobre la realidad social desde una perspectiva intersubjetiva, basada por tanto en el paradigma cualitativo. Los datos con los que se trabaja son datos visuales, los cuales "se han convertido en un enfoque destacado en la investigación cualitativa en general, después de haberse utilizado durante algún tiempo en áreas como la antropología visual” (Banks, 2010, p. 17).

Algunos autores (Ferrándiz, 2011; Baer y Schnettler, 2009) han hecho referencia a la tradicional exclusión de lo visual y a la escasez de reflexiones sobre el empleo del video en la investigación social. Si bien el uso de imágenes ofrece claras limitaciones en cuanto a su objetividad y precisión, su riqueza reposa en la subjetividad, el realismo y la reflexividad que ofrecen en el estudio de la realidad social.

Para García-Gil (2011) emplear la imagen audiovisual en la investigación social implica considerarla "no solo como instrumento para almacenar, comprobar y 
verificar datos, sino como objeto y estrategia de investigación que posibilita el análisis y la reconstrucción de la realidad, así como diferentes lecturas de la misma" (p. 3). Esta autora defiende el uso de las imágenes en la investigación social y considera que el video en la investigación en comunicación (social, audiovisual, periodística) "puede ser empleado tanto como herramienta de trabajo, en cuanto permite el seguimiento al objeto de estudio, o como producto final" (p. 4). La investigación que presentamos aquí respondería a este último uso de la imagen, entendiendo el video como producto final al transformarse en "una forma de indagar y recoger información, así como de construir y reconstruir realidades, no solo desde quien investiga sino también desde las personas o comunidades que narran su situación a través de las imágenes en movimiento" (p. 4).

Desde esta perspectiva, el principal referente audiovisual que hemos empleado para producir esta investigación es el documental de investigación Crónica de un verano (1961), obra emblemática del sociólogo Edgar Morin y del antropólogo Jean Rouch, en la que ambos investigadores salen con la cámara por las calles de París interrogando a los viandantes sobre diversas cuestiones sin dar nada por supuesto, cuestionándose social y filosóficamente sobre la representación del otro y buscando su comprensión a través del aparato cinematográfico.

En nuestro caso, el ejercicio de hacer converger las posiciones de los individuos en un escenario público a través del registro audiovisual llevó a reafirmar la importancia de la cámara de video como útil facilitador de la investigación dentro de las ciencias sociales, entendida como un instrumento que facilita la representación de la realidad y la comprensión de la misma (Buxó y de Miguel, 1999) a partir de técnicas de observación, exposición, interacción o de reflexión de las dinámicas y contenidos temáticos que se registran ante ella (Nichols, 1997).

El trabajo responde entonces a un proyecto de investigación exploratoria basado en unas preguntas y objetivos y una metodología de investigación, y su fin último es la producción de un documental audiovisual. Barroso (1994, p. 87) define al documental como un género audiovisual basado en una narración que tiene por objeto dar cuenta de "la realidad de los hombres y mujeres contemporáneos sin que 
su mirada esté supeditada a los imperativos de la actualidad ni a los criterios de la noticiabilidad, ofreciendo una interpretación creativa de la realidad”.

En este sentido, cabe resaltar que este ejercicio exploratorio encaja también en la reciente teorización de las prácticas de comunicación para la paz, en tanto se convirtió en sí mismo en un espacio que activó el diálogo ciudadano mediante un debate democrático, que es precisamente una de las herramientas que sirve a la reconstrucción del tejido social mediante procesos de autorreconocimiento y reconocimiento de la diferencia, enmarcado todo ello en los límites del respeto y la tolerancia (Unesco, 2014; Bayuelo et al., 2008; Franco, Nieto y Rincón, 2003).

Todos estos planteamientos sirven como base para soportar esta investigación y evidenciar la importancia que tiene el otorgar un lugar a las voces de la ciudadanía, para desprenderse de los discursos dominantes y lograr una mayor comprensión de eventos políticos de gran transcendencia como lo fue en este caso el plebiscito para refrendar el acuerdo entre el Gobierno colombiano y la guerrilla de las Farc.

\section{Metodología EMPLEADA}

¿Y tú qué vas a hacer con tu voto? es una investigación de carácter cualitativo cuyo resultado han sido dos productos audiovisuales que recopilan una serie de testimonios que se dieron en diversos escenarios de la ciudad en los días previos al plebiscito inspirándose metodológicamente en el ejercicio periodístico del vox populi.

\section{Técnica de recolección de la información}

Según el manual de estilo de RTVE, la técnica del vox populi no es más que una encuesta a pie de calle que carece de valor estadístico y que sirve como ilustración de un tema de actualidad, sin pretender extraer conclusiones con ello. Consiste en tomar aleatoriamente una muestra de entrevistados que, por su condición demográfica, formen parte del público objeto de estudio, y entrevistarles mediante preguntas 
sencillas, de fácil comprensión, que no contengan implícita la respuesta para que las personas entrevistadas expresen su opinión de forma libre y espontánea (RTVE, s. f.).

Desde esta premisa, nuestro ejercicio consistió en salir a las calles de Cartagena tres semanas previas a la celebración del plebiscito, interrogando a los viandantes en distintos puntos de la ciudad sobre el sentido de su voto. Con esta intención se elaboraron tres pendones que tenían como fin atraer la atención de los ciudadanos y crear un set ficticio (Figura 2).

Para el proyecto era pertinente generar una discusión abierta en la cual no hubiese censura o sesgo político y donde cualquiera pudiese participar sin distinción. La necesidad de crear una atmósfera de tolerancia era inherente al ejercicio: los integrantes del grupo de investigación debían mostrarse como seres apolíticos, evitando que los ciudadanos se cohibieran de participar, y mostrando una actitud permanente de escucha activa.

Figura 2. Preparación de los pendones en la Plaza de los Estudiantes del centro histórico de Cartagena

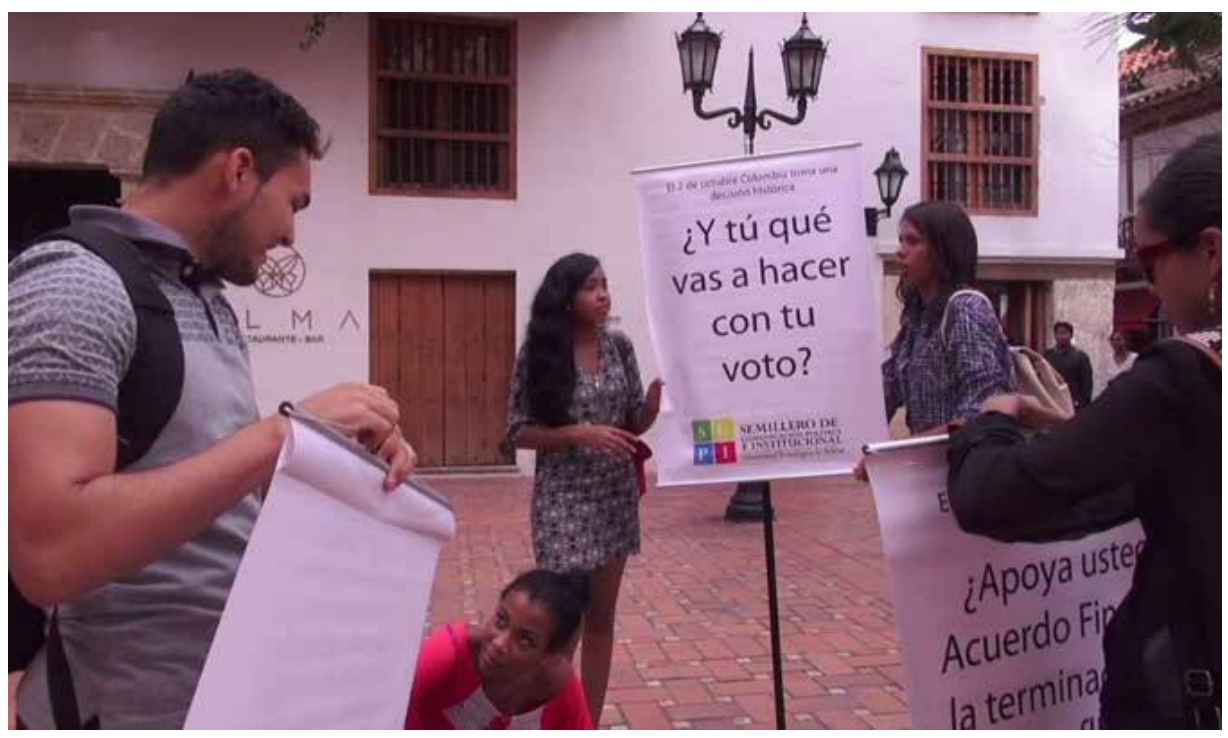

Fuente: elaboración propia. 
En uno de ellos reposaba la pregunta del plebiscito: ¿Apoya usted el acuerdo final para la terminación del conflicto y la construcción de una paz estable y duradera?, y en los otros dos, precedidos de la frase: "El 2 de octubre Colombia toma una decisión histórica", se utilizó la pregunta de nuestra investigación: ¿Y tú qué vas a hacer con tu voto? Estas preguntas pretendían llamar la atención de los viandantes e iniciar el debate público para identificar la relación de los argumentos expuestos por los ciudadanos, desde su posición personal, el contexto sociopolítico y la intención de voto.

Figura 3. Extracto del documental con los pendones de fondo

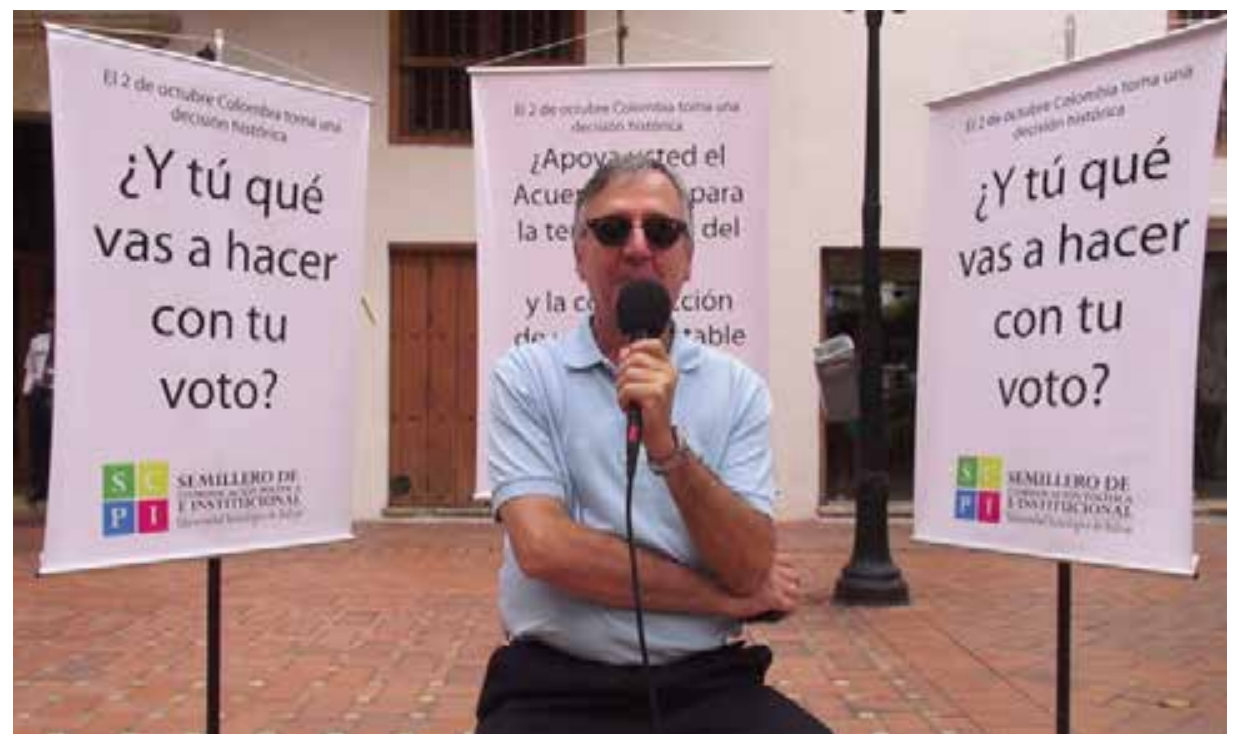

Fuente: elaboración propia.

Desde el punto de vista de la realización audiovisual se optó por el uso de dos cámaras: la denominada cámara 1 aportaría una mirada fija de aquellas personas que, voluntariamente, se acercaban a participar agarrando intencionalmente un micrófono de mano y ubicándose en el set creado con ayuda de los pendones. 
Por su parte, la cámara 2 permitiría a los realizadores interactuar con el escenario y los actores, recogiendo las discusiones de otros ciudadanos que se escapaban del foco de la cámara principal pero que se derivaban de lo que se decía ante ella.

Figura 4. Fotograma de una de las discusiones registradas con la cámara 2

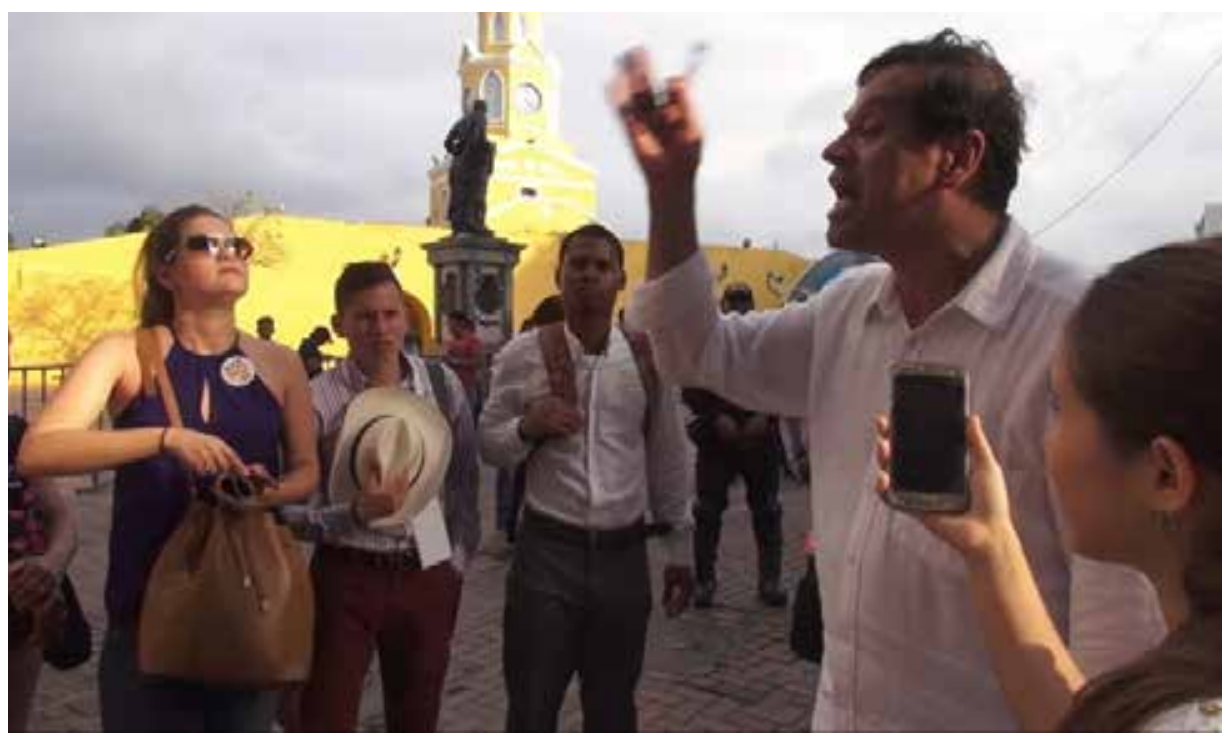

Fuente: elaboración propia.

Durantela fase dela producción audiovisual se buscó intencionalmente la combinación de dos de los estilos de representación audiovisual propuestos por Ferrándiz (2011, pp. 153-154) a partir de la obra del teórico documentalista Bill Nichols (1997): el denominado estilo de exposición ("donde la lógica de la argumentación oral tiene precedencia respecto a la continuidad temporal y espacial de las imágenes”, p. 153), y el estilo interactivo ("usando intencionalmente la cámara para provocar situaciones en el campo", p. 154).

\section{Muestra y período de recogida de la información}

El trabajo de campo se realizó en cinco días distribuidos alternativamente durante las tres semanas previas a la cita con las urnas en diversos puntos de la ciudad. En 
cuanto a la población objeto de estudio, el objetivo era interrogar a todas las personas habilitadas para votar que quisieran expresar sus argumentos ante la cámara. Para ello se combinaron dos tipos de muestra:

- Una muestra espontánea, recogida durante los primeros días de rodaje en diversos espacios públicos de Cartagena (universidades, entradas de centros comerciales y calles y plazas de diversos sectores de la ciudad: Ternera, La Castellana, Centro y Getsemaní).

- Una muestra intencional, recogida el 26 de septiembre, día de la firma del Acuerdo de Paz en el Centro de Convenciones de Cartagena y día final de rodaje. Aquel día visitamos expresamente una concentración de partidarios del Sí junto al estadio de fútbol Jaime Morón, para después acudir a la concentración de los partidarios del No en el barrio de El Cabrero.

El proyecto de investigación ha pretendido incluir la voz de diversos sectores socioeconómicos y políticos de Cartagena, al desplazarse por diferentes locaciones a lo largo de la ciudad buscando en ellas una representación de los argumentos que pudieran estar delimitados por las zonas físicas y económicas de la ciudad.

\section{Equipo de investigación y equipo técnico empleado}

El equipo de producción final estuvo conformado por cuatro estudiantes del semillero y dos docentes del programa de Comunicación Social de la Universidad Tecnológica de Bolívar. Además, a lo largo del proceso otros estudiantes se fueron uniendo esporádicamente al proyecto debido al interés que les despertaba. Para la posproducción se unió al equipo un auxiliar del Centro de Medios de la Universidad experto en edición audiovisual.

El equipo técnico se componía de dos cámaras de video Sony NX30 y un micrófono cardioide dinámico modelo Senheiser E835 y dos trípodes de video profesional. Para la toma de sonido se empleó este micrófono para recoger los testimonios frente a la 
cámara y el micrófono de la cámara para registrar las interacciones del público. El material audiovisual se editó en el programa de edición Final Cut.

\section{Resultados Y DisCUSIÓN}

Durante el trabajo de campo se encontraron más argumentos que respaldaron el $S i$ en comparación al $N o$. Si bien este dato es anecdótico y carente de representatividad, coincide con los resultados del plebiscito para la ciudad de Cartagena donde, de las 146235 personas que salieron a votar, 81500 optaron por el Si frente a 64735 que votaron por el No. La abstención fue del 80 \% (Taborda, 2016).

Empero, los resultados a nivel nacional fueron diferentes: el No obtuvo un $50.21 \%$ de los votos, frente al $49.78 \%$ que obtuvo el Sí, mostrando un país dividido frente a los acuerdos entre sus partidarios y sus detractores. El plebiscito mostró además un escaso nivel de participación: de los casi 35 millones de ciudadanos llamados a las urnas, únicamente el $37.43 \%$ hizo uso de su derecho al voto (Registraduría Nacional del Estado Civil, 2016). Esta fue además la cita a urnas de carácter nacional que tuvo menor grado de participación en dos décadas.

De cualquier forma, y como ya se ha indicado, la investigación videodocumental no pretendía tener un carácter representativo sino ilustrativo, documentando el clima de opinión existente en el período previo a la votación. En esto influyó el hecho de que su proceso de edición tuviera lugar meses después de conocerse el resultado final que dieron las urnas y se considerase la necesidad de reflejar la polarización resultante.

Consideramos que el visionado de ambos materiales recoge argumentos y opiniones que ofrecen hoy nuevas lecturas sobre la comprensión de la situación del presente período de posconflicto en Colombia tras la desmovilización de las Farc y la victoria electoral en 2018 del actual presidente colombiano Iván Duque, máximo responsable del devenir del proceso de paz, quien procede ideológicamente de las filas de los partidarios del No. De igual modo desde una mirada internacional, las posiciones de la ciudadanía de Cartagena reflejadas en el documental simbolizan de alguna manera 
algunos de los grandes debates y dilemas presentes en los conflictos políticos de las democracias occidentales contemporáneas.

Tras finalizar el rodaje el equipo había registrado un aproximado de 11 horas de grabación y más de 140 testimonios. De este material audiovisual surgieron dos productos audiovisuales. El primero de ellos $-\mathrm{y}$ al que hace referencia este artículo¿Y tú qué vas a hacer con tu voto??, de seis minutos de duración, se construyó como un material corto destinado a incitar la discusión ciudadana en diversos espacios públicos (escuelas, universidades, colectivos de comunicación, grupos comunitarios, etc.) permitiendo entablar diálogos entre las posiciones que se manejan en el territorio referentes a la consolidación del proceso de paz en la nueva dinámica social a la que se enfrenta el país. El ejercicio de contraponer las diferentes posturas ante el proceso da pie a diversas reflexiones sobre las posibilidades que ofrece el medio audiovisual para posibilitar una construcción conjunta de significados.

El segundo producto, Argumentos ${ }^{6}$, es un largometraje documental que surgió desde la idea de aprovechar el rico material recogido durante el trabajo de campo, pero con una mayor profundización y con una clara vocación de documentar una etapa crucial de la historia del país.

\section{Tratamiento y análisis del material audiovisual}

Para el tratamiento del material recogido se contó con la colaboración de uno de los auxiliares de producción del Centro de Medios de la Universidad en calidad de montador/editor. Su presencia aportaba la necesaria mirada de alguien que no había estado presente durante el trabajo de campo y que se ceñía a lo que estaba registrado en las imágenes.

Siendo conscientes de abordar una cuestión controvertida como lo era la postura frente al plebiscito, durante el proceso de edición se decidió incluir en ambos

5. ¿Y tú qué vas a hacer con tu voto? puede ser visto en el siguiente enlace: https://vimeo.com/253997985

6. Argumentos puede ser visto en el siguiente enlace: https://www.youtube.com/watch?v=01St9Py7kyQ 
productos un número equitativo de posturas frente al Sí y frente al No. La intención de ambas producciones no era la de condicionar el voto en ninguno de los dos sentidos, ni tampoco la de realizar crítica alguna sobre cualesquiera de las posiciones reflejadas, sino la de poder abarcar una riqueza de testimonios y puntos de vista de los ciudadanos, cumpliendo el objetivo de ilustrar el clima de opinión frente al proceso.

Para la elaboración del guion de montaje varios miembros del semillero visionaron de manera independiente el material, siguiendo el criterio de Barroso (1994, p. 144) de seleccionar las imágenes y testimonios más adecuados "en función de sus posibilidades expresivas y plásticas". No se partía de una escaleta o estructura previa, por lo que el guion documental de ambos productos se realizó tras debatir y consensuar entre los integrantes del grupo una estructura narrativa y una selección concreta de clips de video. Al fraccionar la información en dos piezas se pretendía la investigación en el ojo público antes y después del proceso electoral.

Argumentos tiene una duración total de una hora y quince minutos. Para su realización se optó por una estructura narrativa clásica lineal empleando una selección del material recogido que presentara de forma equitativa las dos posturas. Como recursos narrativos, además de la selección de imágenes registradas durante el trabajo de campo, se emplearon imágenes de archivo procedentes de noticieros y canales oficiales, y se insertaron títulos con las localizaciones y fechas de las tomas de los registros. Se evitó el uso de la voz en off así como cualquier otro elemento que pudiera condicionar la mirada del espectador.

El documental se inicia con una introducción que presenta al presidente Santos anunciando la consecución del acuerdo con las Farc, a la que se contrapone el argumento de una ciudadana en contra del mismo que afirma ser capaz de "caer en el piso para defender esta patria, así nos toque matar guerrilleros uno por uno, así nos armemos...", tras lo cual se muestra una fuerte discusión verbal ocurrida el día de la firma del acuerdo en la Plaza de los Coches entre un ciudadano defensor del Sí y un grupo de partidarios del No. 
Después, el documental se desarrolla estructurándose narrativamente en un solo bloque de varias secuencias que transcurren en diversos barrios de la ciudad: la sede de la Universidad Tecnológica de Bolívar en el barrio de Ternera, el Paseo de la Castellana, el centro histórico, Getsemaní, Olaya y El Cabrero. Estos barrios fueron elegidos con la intención de representar diversos estratos sociales de la ciudad. Si bien en ninguno de ellos predominó significativamente una u otra postura, el día de la firma de los acuerdos el barrio de El Cabrero, uno de los barrios residenciales de Cartagena, acogió la concentración de los partidarios del No, mientras que Olaya, uno de los sectores populares de Cartagena, acogió a los del Sí. Las diferentes secuencias de este bloque fueron incorporadas al montaje audiovisual en el mismo orden temporal en que fueron recogidos los testimonios.

La conclusión termina con el uso de imágenes de archivo extraídas del noticiero RCN del día 2 de octubre con la presentadora Claudia Gurisatti informando sobre el triunfo del $N o$, y de las imágenes del comunicado oficial por parte de la academia sueca del galardón otorgado al presidente Santos como premio Nobel de la Paz una semana después del plebiscito. Por último, los títulos de crédito se muestran acompañados por la música del himno nacional de Colombia, cuyas frases son cantadas frente a la cámara por varios ciudadanos.

Antes de dar por terminada la versión final del documental, algunas versiones previas se proyectaron a modo de borrador entre diferentes clases de asignaturas del programa de Comunicación Social de la Universidad Tecnológica de Bolívar relacionadas con la producción audiovisual. La retroalimentación recibida por parte de estudiantes y profesores sirvió para modificar la duración inicial del producto, así como para mejorar su estructura narrativa.

\section{Distribución y exhibición del proyecto}

Con el ideal de alcanzar el objetivo de promover el debate y la reflexión ciudadana frente al proceso de paz y utilizar el registro audiovisual como instrumento pedagógico, ambos productos necesitaban ser proyectados en espacios públicos. Para ello se ideó un circuito de exhibición basado en la distribución del producto en redes 
sociales virtuales (utilizando las plataformas YouTube y Vimeo) y su proyección en diferentes espacios académicos y educativos: congresos, charlas, conferencias, etc. Tras haber llevado a cabo las etapas previas de la producción audiovisual (preproducción, producción y posproducción), el desarrollo de este circuito de exhibición supuso una experiencia de aprendizaje para el equipo de investigación.

La exposición mediática del producto corto se hizo a través de un canal en YouTube, alcanzando más de 200 visitas, un número relativamente alto pese a que su publicación se realizó tres días antes de las elecciones. ¿Y tú qué vas a hacer con tu voto? es utilizado hoy en algunas clases dentro del campus universitario de la Universidad Tecnológica de Bolívar (Historia Contemporánea, Análisis Audiovisual, Metodología de la Investigación Cualitativa, Cátedra de Paz) y ha sido presentado en diversas conferencias en universidades y colegios de Cartagena, haciendo parte además de conversaciones informales y públicas a través de redes sociales virtuales, entablando un primer contacto con la audiencia que se vería afectada con los resultados electorales.

El documental largo, por su parte, ha sido proyectado en diversos contextos académicos y culturales en Cartagena (como la Universidad Tecnológica de Bolívar o la Alianza Francesa de Cartagena) y en Cúcuta (donde obtuvo en 2017 el 3er. puesto en el III Encuentro Nacional de Semilleros de Investigación en Comunicación celebrado en la Universidad Francisco de Paula Santander). Además, ha podido ser proyectado en el año 2018 en diversos eventos en Madrid (en el Colegio Oficial de Politólogos y Sociólogos) y en Ciudad de México (en la XII Cumbre Mundial de Comunicación Política). Desde el mes de abril de 2019, y dando por concluido el período de exhibición, el documental está disponible en abierto a través de YouTube.

\section{Conclusiones}

El plebiscito por la paz en Colombia de octubre de 2016 fue una de las convocatorias electorales latinoamericanas que mejor ejemplifica la influencia que han adquirido recientemente los medios sociales a través de las redes sociales virtuales, "como 
herramienta(s) de polarización que refuerza(n) las divisiones políticas existentes en la sociedad" (Campos-Domínguez, 2017, p. 787). Ese mismo ańo tuvieron lugar otras importantes convocatorias electorales como el referéndum sobre la permanencia del Reino Unido en la Unión Europea (en el mes de junio) o las elecciones presidenciales de Estados Unidos (en el mes de noviembre) que demostraron cómo en las democracias occidentales estos nuevos medios de comunicación política se han convertido en un instrumento fundamental de los líderes de opinión, superando el efecto que tienen los medios de comunicación sobre el estado de la opinión pública e influyendo decisivamente en las decisiones y acciones que emprende la ciudadanía.

Todas estas convocatorias mostraron además un escenario de abierta polarización política que afecta a las democracias liberales occidentales. En este período se puso de moda el concepto de posverdad' y la ciudadanía comenzó a descubrir la facilidad con la que se desarrollan y expanden las fake news.

El plebiscito colombiano sobre el acuerdo de paz de 2016 fue una de las primeras citas electorales latinoamericanas cuyo resultado final reflejó no solamente esa polarización entre la opinión pública, sino también el uso deliberado de la desinformación y la importancia que en la actualidad tiene la apelación a la emoción y a las creencias de los votantes a través de Internet, como fue incluso admitido públicamente por el propio gerente de la campaña por el No, Juan Carlos Vélez (Bluradio, 2016).

Es importante resaltar dos factores que influyeron en el resultado del plebiscito colombiano y que son comunes en el actual contexto político latinoamericano: el temor a un contagio de la situación política y económica de Venezuela, y la creciente influencia de las Iglesias evangélicas alineadas junto al conservadurismo político (como sucedió también en las elecciones presidenciales de Costa Rica y de Brasil de 2018).

7. Posverdad: Clavero (2018, p. 169) se refiere al término como una producción intencional de falsedades para engañar al público mediante una distorsión deliberada de la realidad a través de noticias falsas y la construcción de hechos alternativos, cuya expansión se ve facilitada por la revolución digital. Este autor recuerda la importancia que adquirió este término a nivel internacional, cuando el Diccionario Oxford lo eligió como la palabra del año 2016.

8. Fake news: la traducción literal significa "noticias falsas", y Elías (2018, p. 2) define el término como "intoxicación informativa a partir de bulos". 
Figura 5. Extracto del documental en donde uno de los partidarios del No muestra un pendón con los rostros del presidente Juan Manuel Santos, Fidel Castro, Nicolás Maduro y Rodrigo Londoño alias Timochenko

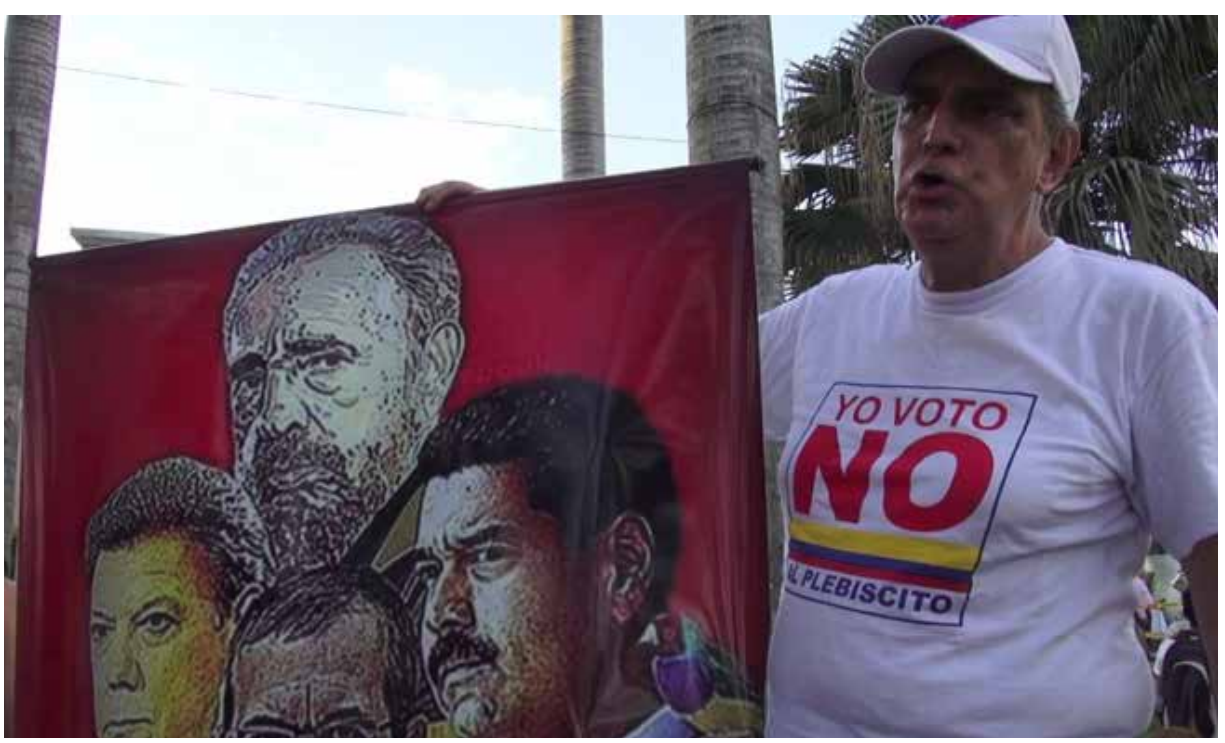

Fuente: elaboración propia.

A partir de todos estos elementos, como comunicadores sociales consideramos que el nuevo reto de la información para el contexto político presente es, paradójicamente, el viejo reto de siempre: aspirar a defender la verdad completa. Esto pasa por descifrar con más inteligencia la mentira y seguir insistiendo en la elaboración de estrategias y mensajes comunicacionales asertivos, basados en narrativas integradoras y representativas que faciliten la consolidación de la paz.

Si bien los datos de esta investigación no son en absoluto generalizables (tampoco pretendían serlo), sí son una representación de lo que las cámaras recogieron durante las tres semanas en las que se llevaron a cabo los registros a pie de calle. A lo largo del ejercicio audiovisual se pudo comprobar in situ esa polarización creciente en la opinión pública de la que las encuestas no hablaban. 
Con la difusión posterior de ¿Y tú qué vas a hacer con tu voto? y de Argumentos, se ha reforzado el potencial pedagógico que pretendía el hecho de elegir el audiovisual como formato para albergar la investigación. "Las imágenes, precisamente porque pueden admitir múltiples lecturas dependiendo del contexto social y personal del espectador, permiten formas múltiples de análisis" (Banks, 2010, p. 159). Durante el circuito de exhibición de ambas piezas hemos podido comprobar el debate que se produce entre los espectadores tras la proyección, lo que confirma que la ciudadanía sigue dispuesta a reflexionar sobre qué es Colombia y qué clase de paz se espera consolidar en el territorio.

Como ejercicio formativo fruto de un semillero de investigación, el resultado fue satisfactorio puesto que conectó a los estudiantes con su realidad política más cercana de forma creativa e innovadora a través del uso del medio audiovisual, una herramienta que, junto con la salida a campo, favorece la motivación de los estudiantes. El proyecto, realizado entre docentes y estudiantes, se configuró como una apuesta para mostrar la forma en que la comunicación sirve a la construcción de paz, creando escenarios de encuentro, debate y diálogo frente a la cámara audiovisual para que los ciudadanos pudieran expresar, desde su propia realidad política y social, su posición en un contexto de país que apuesta a diferentes concepciones de paz.

El proceso de realización audiovisual al que dio vida esta investigación exploratoria se convirtió en un aprendizaje para los participantes en tanto demostró que la realidad social puede ser mejor comprendida a partir de la mirada sobre la propia experiencia vital del individuo frente al conflicto armado, y del análisis de los discursos presentes en el ejercicio de autorreconocimiento ciudadano; es decir, desde un abordaje que se aleja de las opiniones dictadas por las maquinarias mediáticas tradicionales para comprender más bien sus efectos sobre la configuración de la opinión pública ciudadana.

Así mismo, se espera que la reflexión ciudadana generada en torno a la pregunta ¿Y tú qué vas a hacer con tu voto?, pueda promover la proliferación de procesos emocionales, cognitivos y políticos que den paso a la formación de una memoria colectiva ciudadana que permita comprender el pasado, para generar estrategias que 
nos ayuden a construir un mejor futuro (Behar, 2016; Grupo Regional de Memoria Histórica UTB, 2017).

Finalmente, el resultado es un producto destinado a servir a la memoria: dos piezas documentales que, a modo de espejo, narran a los propios colombianos una parte inevitable de la realidad de su país y contribuyen a comprender el espíritu del momento.

\section{REFERENCIAS}

Banks, M. (2010). Los datos visuales en la investigación cualitativa. Madrid, España: Ediciones Morata.

Baer, A., y Schnettler, B. (2009). Hacia una metodología cualitativa audiovisual. El video como instrumento de investigación social. En A. Merlino (coord.), Investigación Cualitativa en las ciencias sociales: temas, problemas y aplicaciones (pp. 149-173). Buenos Aires, Argentina: Cengage Learning.

Barroso, J. (1994). Técnicas de realización de reportajes y documentales para televisión. Madrid, España: IORTV.

Bayuelo, S., Cadavid, A., Durán, O., González, A., Tamayo, C., y Vega, J. (2008). Lo que le vamos quitando a la guerra. Bogotá D. C., Colombia: Centro de Competencia en Comunicación para América Latina.

Behar, O. (2016). Por qué un periodismo que narra la memoria del conflicto armado: la responsabilidad de los medios y periodistas. En J. Cardona (ed.), Pistas para narrar la memoria, periodismo que reconstruye las verdades (pp. 52-69). Bogotá D. C., Colombia: Konrad Adenauer Stiftung.

Bluradio. (2016, 6 de octubre). Las confesiones del gerente de la campaña del No en el Plebiscito por la Paz. Recuperado de https://www.bluradio.com/paz/ tergiversamos-mensajes-porque-los-del-si-tambien-lo-hicieron-juan-carlos-velez-118646 
Boyd, D. (2011). Social network sites as networked publics: Affordances, dynamics, and implications. En Z. Papacharissi (ed.), A networked self. Identity, community and culture on social network sites (pp. 39-58). Londres, Reino Unido: Routledge.

Buxó, M. (1999). ... que mil palabras. En M. Buxó, y J. De Miguel (eds.). De la investigación audiovisual: fotografía, cine, video, televisión (pp. 1-22). Barcelona, España: Cuadernos A.

Buxó, M. J., y De Miguel, J. M. (eds.). (1999). De la investigación audiovisual. Fotografía, cine, vídeo, televisión. Barcelona, España: Proyecto A Ediciones.

Campos-Domínguez, E. (2017). Twitter y la comunicación política. El profesional de la información, 26(5), 785-793. Septiembre-octubre.

Clavero, J. A. (2018). Posverdad y exposición selectiva a fakenews. Algunos ejemplos concretos de Argentina. Revista Contratexto, 29, 167-180.

Colprensa (2016, 24 de agosto). Los intentos frustrados de firmar la paz con las Farc. Recuperado de https:/www.elcolombiano.com/colombia/acuerdos-de-gobierno-y-farc/ los-intentos-frustrados-de-firmar-la-paz-con-las-farc-LK4851580

Elías, C. (2018). Fakenews, poder y periodismo en la era de la posverdad y 'hechos alternativos'. Ámbitos. Revista Internacional de Comunicación, 40, 1-6.

eltiempo.com. (2016, 27 de septiembre). Intención de voto por el Si en el plebiscito está en el 55 \%. Eltiempo.com. Recuperado de http://www.eltiempo.com/politica/proceso-de-paz/ encuesta-del-plebiscito-si-55-por-ciento-51497

eltiempo.com. (2018, 2 de agosto). Infografía: conflicto armado en Colombia dejó más de 260000 muertos. Eltiempo.com. Recuperado de https://www.eltiempo.com/justicia/ conflicto-y-narcotrafico/cifras-del-conflicto-armado-en-colombia-251228

Ferrándiz, F. (2011). Etnografías contemporáneas. Anclajes, métodos y claves para el futuro. Barcelona, España: Anthropos-Universidad Autónoma Metropolitana de México. 
Franco, N., Nieto, P., y Rincón, O. (2003). Las narrativas como memoria, conocimiento, goce e identidad. Tácticas y estrategias para contar. Bogotá D. C., Colombia: Centro de Competencia en Comunicación para América Latina-Friedrich Ebert Stiftung.

García-Gil, M. E. (2011). El video como herramienta de investigación. Una propuesta metodológica para la formación de profesionales en Comunicación. Enlaces: revista del CES Felipe II, 13. Recuperado de http://www.cesfelipesegundo.com/revista/articulos2011/ Monica\%20Garcia.pdf

Grupo Regional de Memoria Histórica UTB. (2017). Hagamos memoria colectiva: relatos, reflexiones, imágenes y ejercicios que aportan a la reconstrucción participativa de la memoria histórica de los Montes de María. Cartagena de Indias, Colombia: Universidad Tecnológica de Bolívar.

Herrera, M. (2013). Medios de comunicación y paz, hacia una cultura liberadora. Revista Semana. Recuperado de https://www.semana.com/opinion/articulo/ medios-comunicacion-paz-hacia-cultura-liberadora/334141-3

Igartua, J. J., y Humanes, M. L. (2010). Teoría e investigación en comunicación social. Madrid, España: Síntesis.

La Rosa, A. (2014). Los medios sociales en el ejercicio del periodismo. Correspondencias \& Análisis, 4, 15-36, enero-diciembre. DOI: https://doi.org/10.24265/cian.2014.n4.01

Lippmann, W. (1922). Public Opinion. Madrid, España: Cuadernos de Langre.

McCombs, M., y Shaw, D. (1972). The Agenda-Setting Function of Mass Media. Public Opinion Quarterly, 36(2), 176-187.

McCombs, M. (2006). Estableciendo la agenda: El impacto de los medios en la opinión pública y en el conocimiento. Barcelona, España: Paidós.

McCombs, M. (2010). Extending our theoretical maps: Psychology of agenda-setting. Central European Journal of Communication, 3(1-4), 197-206. 
Morin, E., y Rouch, J. (1961). Crónica de un verano. Documental audiovisual. Recuperado de https://vimeo.com/54909410

Nichols, B. (1997). La representación de la realidad. Barcelona, España: Paidós.

Noelle-Neumann, E. (2003). La espiral del silencio. Opinión pública: nuestra piel social. Barcelona, España: Paidós.

Registraduría Nacional del Estado Civil. (2 de octubre de 2016). Plebiscito 2 de octubre de 2016. Recuperado de https://elecciones.registraduria.gov.co/pre_plebis_2016/99PL/ DPLZZZZZZZZZZZZZZZZZ_L1.htm

Rincón, O. (2007). La fórmula de la comunicación ciudadana: +ciudadanía + narración + activismo. En AA. VV. Ya no es posible el silencio- Textos, experiencias y procesos de comunicación ciudadana (pp. 5-11). Bogotá D. C., Colombia: Centro de Competencia en Comunicación para América Latina.

RTVE (s. f.). Manual de estilo de RTVE. Directrices para los profesionales. Madrid, España: Radio Televisión Española. Recuperado de http://manualdeestilo.rtve.es/ rne/3-4-generos-de-opinion/3-4-4-la-encuesta-a-pie-de-calle/

Sampedro, V. y Resina, J. (2010). Opinión pública y democracia deliberativa. Una actualización en el contexto digital de la sociedad red. Ponto e Virgula, 8, 1-22. Recuperado de https://revistas.pucsp.br/index.php/pontoevirgula/article/view/13941

Sánchez, G. (2014). Modernización y barbarie: signos convergentes del conflicto armado en Colombia. En Guerrilla y población civil trayectoria de las Farc 1949-2013. Bogotá D. C., Colombia: Centro Nacional de Memoria Histórica. Recuperado de http:// www.centrodememoriahistorica.gov.co/informes/publicaciones-por-ano/2013/ guerrilla-y-poblacion-civil-trayectoria-de-las-farc-1949-2013

Sartori, G. (2007). ¿Qué es la democracia? Madrid, España: Taurus. 
semana.com. (2016a, 10 de septiembre). El Si va ganando en el plebiscito. Semana.com. Recuperado de https://www.semana.com/nacion/galeria/ plebiscito-por-la-paz-en-las-encuestas-el-si-va-ganando/493335

semana.com. (2016b, 2 de octubre). La debacle de las encuestadoras. Semana.com. Recuperado de https://www.semana.com/nacion/articulo/ plebiscito-por-la-paz-encuestadoras-se-equivocaron-con-resultados/496543

Taborda, E. (2016, 4 de octubre). Resultados del plebiscito en Bolívar: así opinan políticos. Eluniversal.com. Recuperado de http://www.eluniversal.com.co/politica/ resultados-del-plebiscito-en-bolivar-asi-opinan-politicos-236987

Tíjaro, A. (2016). Comunicación para la paz. Revista Interacción: CEDAL- Comunicación educativa. Recuperado de http://www.cedal.org.co/es/revista-interaccion/ comunicacion-para-la-paz

Unesco. (2014). Agendas de comunicación en tiempos de conflicto y paz. Cátedra Unesco de comunicación. Bogotá D. C., Colombia: Pontifica Universidad Javeriana. Recuperado de http://www.javeriana.edu.co/unesco/pdf/agendas-comunicacion.pdf 